\title{
Iron intake does not significantly correlate with iron deficiency among young Japanese women: a cross-sectional study
}

\author{
Keiko Asakura ${ }^{1}$, Satoshi Sasaki ${ }^{2, *}$, Kentaro Murakami ${ }^{2}$, Yoshiko Takahashi ${ }^{3}$, Kazuhiro \\ Uenishi $^{4}$, Miki Yamakawa $^{5}$, Yuji Nishiwaki ${ }^{1}$, Yuriko Kikuchi ${ }^{1}$, Toru Takebayashi ${ }^{1}$ and \\ the Japan Dietetic Students' Study for Nutrition and Biomarkers Groupt \\ 'Department of Preventive Medicine and Public Health, Keio University School of Medicine, Tokyo, Japan: \\ ${ }^{2}$ Department of Social and Preventive Epidemiology, School of Public Health, University of Tokyo, 7-3-1 Hongo, \\ Bunkyo-ku, Tokyo 113-0033, Japan: ${ }^{3}$ Department of Public Nutrition, Wayo Women's University, Chiba, Japan: \\ ${ }^{4}$ Laboratory of Physiological Nutrition, Kagawa Nutrition University, Saitama, Japan: ${ }^{5}$ Shinshu University School \\ of Medicine, Nagano, Japan
}

Submitted 21 May 2008: Accepted 2 0ctober 2008: First published online 9 December 2008

\begin{abstract}
Objectives: We evaluated the association of nutrient intake with Fe deficiency with regard to lifestyle factors and health condition in young Japanese women. Uniquely among developed countries, dietary habits render Japanese populations vulnerable to Fe deficiency, owing to their relatively low intake of Fe and high intake of Fe absorption inhibitors, such as green tea and soyabeans.

Design: A cross-sectional study.

Setting and subjects: The subjects were 1019 female Japanese dietetic students aged 18-25 years. Dietary habits during the preceding month were assessed using a previously validated, self-administered, diet history questionnaire. Blood analysis was performed to assess body Fe status. Subjects were categorized with Fe deficiency when their serum ferritin levels were $<12 \mathrm{ng} / \mathrm{ml}$. Twenty-nine dietary variables, i.e. intakes of energy, sixteen nutrients including Fe and twelve food groups, were analysed using multivariate logistic regression models adjusted for possible confounders. Results: Of the subjects, 24.5\% were categorized with Fe deficiency. However, no dietary factors assessed were significantly associated with Fe deficiency. The risk of Fe deficiency was significantly lower in women with infrequent or no menstrual cycles than in those with regular cycles (OR $=0 \cdot 58 ; 95 \%$ CI 0.34, 1.00) and significantly higher in women with heavy menstrual flow than in women with average flow, albeit that these were self-reported (OR $=1 \cdot 83 ; 95 \%$ CI 1·35, 2•48). Conclusions: These results suggest that dietary habits, including Fe intake, do not significantly correlate with Fe deficiency among young Japanese women.
\end{abstract}

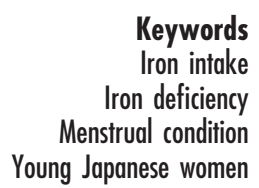

Iron intake

Iron deficiency

Young Japanese women
Fe deficiency remains the most common nutritional deficiency in both developed and developing countries,

\footnotetext{
$\uparrow$ The members of the Japan Dietetic Students' Study for Nutrition and Biomarkers Group (in addition to the authors) are as follows: Mitsuyo Yamasaki, Yuko Hisatomi, Junko Soezima and Kazumi Takedomi (Nishikyushu University); Toshiyuki Kohri and Naoko Kaba (Kinki University); Etsuko Uneoka (Otemae College of Nutrition); Hitomi Hayabuchi and Yoko Umeki (Fukuoka Women's University); Keiko Baba and Maiko Suzuki (Mie Chukyo University Junior College); Reiko Watanabe and Kanako Muramatsu (Niigata Women's College); Kazuko Ohki, Seigo Shiga, Hidemichi Ebisawa and Masako Fuwa (Showa Women's University); Tomoko Watanabe, Ayuho Suzuki and Fumiyo Kudo (Chiba College of Health Science); Katsumi Shibata, Tsutomu Fukuwatari and Junko Hirose (The University of Shiga Prefecture); Toru Takahashi and Masako Kato (Mimasaka University); Toshinao Goda and Yoko Ichikawa (University of Shizuoka); Junko Suzuki, Yoko Niida, Satomi Morohashi, Chiaki Shimizu and Naomi Takeuchi (Hokkaido Bunkyo University); Jun Oka and Tomoko Ide (Tokyo Kasei University); and Yoshiko Sugiyama and Mika Furuki (Minamikyushu University).
}

particularly among adolescent and premenopausal women. In developed countries, for example, the prevalence of Fe deficiency, including depleted Fe stores and Fe deficiency anaemia, among young and middle-aged women is $11 \%$ in the $\mathrm{USA}^{(1)}$ and $18 \%$ in the $\mathrm{UK}^{(2)}$. Moreover, in Japan, Uchida et al. reported in 1992 a prevalence of depleted Fe stores of $41.4 \%$ and of $\mathrm{Fe}$ deficiency anaemia of $8 \cdot 5 \%$ among women aged $11-90$ years $^{(3)}$. Fe deficiency has been related with impaired neuropsychological function ${ }^{(4)}$, reduced worker productivity ${ }^{(5)}$, lowered immunity and decreased metabolic rate $^{(6)}$. Further, Fe deficiency anaemia in pregnancy often contributes to higher child and maternal mortality ${ }^{(7)}$ as well as increased risk of preterm delivery ${ }^{(8)}$. Given that supplementation is considered the most effective treatment, the most common response has been $\mathrm{Fe}$ 
fortification of white flour and other foods, mainly in Western countries.

Several studies in Western countries have reported the important effect of dietary habits on body Fe status ${ }^{(9-11)}$. These studies have shown that increasing total or haem Fe intake correlates with better body Fe status; in other words, higher intake of $\mathrm{Fe}$ is associated with a lower prevalence of Fe deficiency. In apparent contradiction, however, Pynaert et al. recently reported the lack of any significant differences in Fe status parameters between women with high and low Fe intake ${ }^{(12)}$, and called for reconfirmation of the efficacy of increasing Fe intake to improve Fe status.

In addition to Fe itself, several other dietary factors are also known to be associated with Fe levels in man. Absorption is improved by vitamin $\mathrm{C}$ and animal tissues such as meat, poultry and fish, but inhibited by phytate, polyphenols, vegetable proteins and $\mathrm{Ca}^{(2)}$. Several lifestyle factors also have considerable effects on body Fe status. Intensive sports and excessive menstrual blood loss are important risk factors for Fe deficiency ${ }^{(13,14)}$. In particular, menstrual blood loss is thought to be a major cause of deficiency in women ${ }^{(9,14-16)}$.

To our knowledge, however, no study has examined the correlation between $\mathrm{Fe}$ status and dietary intake measured quantitatively with respect to lifestyle factors and health condition in Asia. Foo et al. examined Fe status and dietary Fe intake among Malaysian adolescents aged 12-19 years ${ }^{(17)}$, but did not describe the association between Fe status and Fe intake; while Thankachan et al. showed that inadequate intake of Fe and micronutrients is responsible for the high prevalence of Fe deficiency in India ${ }^{(18)}$, but did not refer to lifestyle factors. Thus, the association of dietary habits with Fe deficiency in consideration of lifestyle factors is not clearly known in Asia, including Japan.

Because it combines Asian dietary habits with a level of development comparable to that of Western countries, Japan may be considered unique among Asian countries. Major distinctions of Japanese dietary habits related to Fe intake include lower meat consumption, which results in lower total Fe intake, particularly lower haem Fe intake, vis-à-vis the intake of higher amounts and a wider range of inhibitors of Fe absorption, such as soyabeans and green tea, which are traditional Japanese foods ${ }^{(19-25)}$. In the present study, we examined the association of $\mathrm{Fe}$ deficiency and quantitative dietary intake with regard to lifestyle and health-related factors in Japan.

\section{Methods}

\section{Subjects}

The present study was based on a multi-centre nutritional survey conducted from February to March 2006 and from January to March 2007 among female dietetic students from fifteen institutions in Japan. All measurements at each institution were conducted according to the survey protocol. Briefly, staff at each institution explained an outline of the survey to potential subjects. Subjects who responded positively were then provided detailed written and oral explanations of the general purpose and procedure of the survey. A total of 1176 women ( 474 women in 2006 and 702 women in 2007) took part in the survey. The study protocol was approved by the Ethics Committee of the National Institute of Health and Nutrition, and written informed consent was obtained from each subject and also from a parent for subjects aged less than 20 years.

\section{Dietary assessment}

Dietary habits during the preceding month were assessed using a previously validated, comprehensive, self-administered diet history questionnaire (DHQ) ${ }^{(26-29)}$. All answered DHQ, as well as a lifestyle questionnaire, were checked at least twice for completeness and when necessary reviewed with the subject to ensure the clarity of answers.

The DHQ is a 16-page structured questionnaire that consists of the following seven sections: (i) general dietary behaviour; (ii) major cooking methods; (iii) consumption frequency and amount of six alcoholic beverages; (iv) consumption frequency and semi-quantitative portion size of 122 selected food and non-alcoholic beverage items; (v) dietary supplements; (vi) consumption frequency and semi-quantitative portion size of nineteen cereals usually consumed as staple foods (rice, bread and noodles) and miso (fermented soyabean paste) soup; and (vii) open-ended items for foods consumed regularly (at least once per week) but not appearing in the DHQ. Items and portion sizes were derived primarily from data in the National Nutrition Survey of Japan and several recipe books for Japanese dishes ${ }^{(27)}$. Information on dietary supplements, including Fe supplements, and data from open-ended questionnaire items were not used in the dietary intake calculation. Estimates of dietary intake for a total of 150 food items, energy and selected nutrients were calculated using an ad boc computer algorithm for the DHQ, based on the Standard Tables of Food Composition in Japan ${ }^{(30)}$. Nutrient and food intakes were energy-adjusted using the density method, i.e. percentage of energy for energy-providing nutrients and amounts per $4184 \mathrm{~kJ}$ (1000 kcal) of energy for other nutrients and foods.

A detailed description of the validity of the DHQ with respect to commonly studied nutritional factors and the methods used to calculate dietary intake have been published elsewhere ${ }^{(26-29)}$. For example, Pearson's correlation coefficients between the DHQ and $3 \mathrm{~d}$ estimated dietary records were 0.48 for energy, 0.48 for protein, 0.55 for fat, 0.48 for carbohydrate and 0.40 for Fe in fortyseven women ${ }^{(27)}$. Further, Pearson's correlation coefficients 
between the DHQ and $16 \mathrm{~d}$ weighed dietary records among ninety-two women were 0.32 for energy, 0.47 for protein, 0.56 for fat, 0.60 for carbohydrate and 0.63 for Fe (S Sasaki, unpublished results). These correlation coefficients are acceptable, because they are similar to those of other selfadministered dietary assessment methods developed and widely used in other countries.

Intakes of haem $\mathrm{Fe}$, non-haem $\mathrm{Fe}$, phytate and bioavailable Fe were estimated using DHQ data. Haem Fe was assumed to constitute $40 \%$ of total $\mathrm{Fe}^{(31)}$, including that in meat and fish. The remaining total Fe intake was assumed to be non-haem Fe. Because we had insufficient information on the phytate content in Japanese food, we used dietary composition data from other countries ${ }^{(32-35)}$. Bioavailable Fe is the amount of Fe actually absorbed and utilized in the body, and is determined by several factors, including intake of phytate, $\mathrm{Ca}$, vitamin $\mathrm{C}$, meat, fish, tea and coffee and the individual's Fe status. Of several algorithms developed to estimate bioavailable $\mathrm{Fe}^{(31,36-40)}$, we estimated its intake based on that by Bhargava et al. ${ }^{(37)}$ (Table 1). Briefly, total bioavailable Fe was obtained by summing bioavailable haem $\mathrm{Fe}$ and bioavailable non-haem Fe, with bioavailable haem Fe calculated by multiplying haem Fe intake by a constant determined in accordance with the individual's Fe status. Three possible scenarios of body Fe reserve were considered: (i) $500 \mathrm{mg}$ (adequate reserve); (ii) $250 \mathrm{mg}$ (median reserve), at which functional alterations due to Fe deficiency had likely not occurred; and (iii) $0 \mathrm{mg}$, at which functional alterations might already have become apparent. Bioavailability of non-haem Fe was calculated for each body Fe reserve by multiplying bioavailability derived from adjustment for an enhancement factor and bioavailability derived from adjustment for phytate. The enhancement factor was obtained by summing the intake of meat (g), fish (g) and vitamin C $(\mathrm{mg})^{(36)}$. Bioavailable non-haem $\mathrm{Fe}$ was derived from the product of non-haem Fe intake and bioavailability of non-haem Fe. In addition, we adjusted for the effect of black tea and coffee, as well as for that of $\mathrm{Ca}$, using the algorithm of Zijp et al. ${ }^{(41)}$. Bioavailability of non-haem Fe was multiplied by 0.8 if intake of black tea and coffee was $450 \mathrm{ml} / \mathrm{d}$ or more, and total bioavailable Fe was multiplied by 0.5 if $\mathrm{Ca}$ intake was more than $300 \mathrm{mg} / \mathrm{d}$.

\section{Diagnostic criteria of depleted Fe stores and Fe deficiency anaemia}

Body Fe status was assessed using blood analysis for serum $\mathrm{Fe}$, ferritin and $\mathrm{Hb}$ concentrations. In accordance with the survey protocol, blood samples were transported

Table 1 Algorithm for the estimation of bioavailable iron intake*

1. Total bioavailable $\mathrm{Fe}(\mathrm{mg})$ :

If $\mathrm{Ca}$ intake is $\leq 300 \mathrm{mg} / \mathrm{d}$

Total bioavailable $\mathrm{Fe}=$ bioavailable haem Fe $(\mathrm{BHI})(\mathrm{mg})$ + bioavailable non-haem Fe (BNI) (mg)

If $\mathrm{Ca}$ intake is $>300 \mathrm{mg} / \mathrm{d}$

Total bioavailable $\mathrm{Fe}=(\mathrm{BHI}+\mathrm{BNI}) \times 0 \cdot 5 t$

2. $\quad \mathrm{BHI}=$ haem Fe intake $(\mathrm{mg}) \times 0.23($ body Fe reserve $=500 \mathrm{mg})$

$\times 0.28$ (body Fe reserve $=250 \mathrm{mg}$ )

$\times 0.35$ (body $\mathrm{Fe}$ reserve $=0 \mathrm{mg}$ )

2.1. Haem Fe intake $(\mathrm{mg})=\mathrm{Fe}$ intake from meat, fish and poultry $(\mathrm{mg}) \times 0.4$

3. $\quad \mathrm{BNI}=$ non-haem Fe intake $(\mathrm{mg}) \times$ bioavailabitity of non-haem $\mathrm{Fe}(\mathrm{BANI})(\%) / 100$

3.1. Non-haem Fe intake $(\mathrm{mg})=$ total Fe intake - haem Fe intake

3.2. $\mathrm{BANI}=$ bioavailability derived from adjustment for $\mathrm{EF} \S$

$\times$ bioavailability derived from adjustment for phytates

$\times$ bioavailability derived from adjustment for black tea \& coffee

3.2.1. Bioavailability derived from adjustment for EF (BAEF) (\%):

If $E F \geq 75$ units, $B A E F=8$ (body $F$ reserve $=500 \mathrm{mg}$ )

$=12$ (body Fe reserve $=250 \mathrm{mg})$

$=20$ (body $\mathrm{Fe}$ reserve $=0 \mathrm{mg}$ )

If $\mathrm{EF}=0$ units, $\mathrm{BAEF}=3$ (body $\mathrm{Fe}$ reserve $=500 \mathrm{mg}$ )

$=4$ (body $\mathrm{Fe}$ reserve $=250 \mathrm{mg})$

$=5($ body $\mathrm{Fe}$ reserve $=0 \mathrm{mg})$

If $E F>0$ and $<75$ units, $B A E F=3+8.93 \log _{n}[(E F+100) / 100]($ body Fe reserve $=500 \mathrm{mg})$

$=4+14 \cdot 296 \log _{n}[(E F+100) / 100]($ body Fe reserve $=250 \mathrm{mg})$

$=5+26 \cdot 804 \log _{n}[(E F+100) / 100]($ body $\mathrm{Fe}$ reserve $=0 \mathrm{mg})$

3.2.2. Bioavailability derived from adjustment for phytates (BAP) (\%):

If phytates intake is $\leq 2.88 \mathrm{mg}, \mathrm{BAP}=100$

If phytates intake is $>2.88 \mathrm{mg}, \log _{10} \mathrm{BAP}=-0.2869 \log _{10}[$ phytates intake $(\mathrm{mg})]+0 \cdot 1295$

3.2.3. Bioavailability derived from adjustment for black tea \& coffee (BATC):

If the intake of black tea \& coffee is $\geq 450 \mathrm{ml} / \mathrm{d}$, BATC $=0.8+$

*Mainly derived from the algorithm reported by Bhargava et al. ${ }^{(37)}$.

tFrom Zijp et al. ${ }^{(41)}$.

‡Eggs and dairy products are included in non-haem Fe.

$\S E F=$ vitamin $C(\mathrm{mg})+$ meat $(\mathrm{g})$; 'meat' includes meat, fish and poultry. 
at $-20^{\circ} \mathrm{C}$ by car or aeroplane to ensure delivery to a laboratory in Tokyo, Japan (SRL Inc. in 2006 and Mitsubishi Kagaku Bio-Clinical Laboratories Inc. in 2007) and assayed within $1-2 \mathrm{~d}$ of collection to avoid significant degradation. The colorimetric method (Nitroso-PSAP method) was used to measure serum $\mathrm{Fe}$, and chemiluminescent enzyme immunoassay (CLEIA method) to measure serum ferritin.

Depleted Fe stores was diagnosed when serum ferritin levels were $<12 \mathrm{ng} / \mathrm{ml}$ and $\mathrm{Hb}$ concentrations were $\geq 12 \mathrm{~g} / \mathrm{dl}$; and Fe deficiency anaemia when serum ferritin levels were $<12 \mathrm{ng} / \mathrm{ml}$ and $\mathrm{Hb}$ concentrations were $<12 \mathrm{~g} / \mathrm{dl}^{(42,43)}$. 'Fe deficiency' included both depleted Fe stores and Fe deficiency anaemia.

\section{Otber variables}

Residential areas were grouped into three categories: (i) north (Hokkaido, Tohoku and Kanto); (ii) central (Tokai, Hokuriku, and Kinki); and (iii) south (Kyushu and Chugoku), based on the regional blocks used in the National Nutrition Survey in Japan (hereafter referred to as 'residential block'). They were also grouped into three categories according to population size: (i) city with population $\geq 1$ million; (ii) city with population $<1$ million; and (iii) town or village (hereafter referred to as 'size of residential area'). Current smoking status was selfreported in the lifestyle questionnaire, while current dietary supplement use and alcohol intake were assessed in the DHQ. Alcohol drinking status was divided into three categories: (i) non-drinker; (ii) drinker $1(>0 \%$ to $<1 \%$ of total energy intake); and (iii) drinker $2(\geq 1 \%$ of total energy intake). BMI was calculated as body weight (kilograms) divided by the square of body height (metres). Menstrual cycle and the amount of menstrual flow during the preceding 12 months were also selfreported in the lifestyle questionnaire. With regard to menstrual cycle, the 'regular' category included the number of subjects who replied 'always regular' and 'almost always regular'; 'irregular' included those replying 'half-regular and half-irregular'; and 'infrequently or none' included 'mostly irregular', 'almost none' and 'none'. For amount of menstrual flow, the 'light' category included 'light flow'; 'average' included 'average flow' and 'bleeding with mucus'; and 'heavy' included 'heavy flow' and 'bleeding with clots'. Physical activity was computed as average MET-h/d (where MET = metabolic equivalent) ${ }^{(44)}$ on the basis of the frequency and duration of five different activities (sleeping, high- and moderate-intensity activities, walking and sedentary activities) over the preceding month, as reported in the lifestyle questionnaire ${ }^{(45)}$.

\section{Statistical analysis}

Subjects for analysis were identified as described below. In total, 466 women aged 18-25 years enrolling in 2006 and 677 enrolling in 2007 underwent peripheral blood examination. Subjects were excluded from the study if they had missing covariate information ( $n$ 29); extremely low or high daily energy intake $(\leq 4184$ or $\geq 14644 \mathrm{~kJ}$ ( $\leq 1000$ or $\geq 3500 \mathrm{kcal}$ ); $n 31$ ); were using Fe supplements ( $n$ 50; two subjects using Fe preparations as therapy for anaemia were included as patients with Fe deficiency anaemia); had asthma (allergic), thyroid disease, diabetes mellitus, renal disease or gastrointestinal disease ( $n$ 34); or showed both decreased values for $\mathrm{Hb}$ and normal or increased values for ferritin ( $n$ 11). Of these last eleven subjects, we assumed normal body Fe status in eight, mild Fe deficiency anaemia in one, Fe deficiency anaemia under Fe supplementation in one, and a haematological disorder other than Fe deficiency anaemia in one. As some subjects were in more than one exclusion category, the final analysis sample comprised 1019 women.

The associations between Fe deficiency and a number of dietary variables, lifestyle variables and health condition were examined. These included twenty-nine dietary variables, i.e. intakes of energy $(\mathrm{kJ} / \mathrm{d})$, sixteen nutrients (protein, carbohydrate, fat, total dietary fibre, $\mathrm{Ca}$, total $\mathrm{Fe}$, haem $\mathrm{Fe}$, non-haem Fe, bioavailable Fe (three values for each body Fe reserve), phytate, vitamin A, vitamin C, vitamin D, $\alpha$-tocopherol, vitamin $\mathrm{B}_{12}$ and folic acid), ten food groups (meat, fish, cereals, dairy products, green vegetables, other vegetables, pulses, potatoes, fruits and eggs), black tea and coffee; three lifestyle variables (current smoking status (yes; no), alcohol drinking status (non-drinker; drinker 1; drinker 2 ) and physical activity (divided into tertiles)); and BMI $\left(<18.5 \mathrm{~kg} / \mathrm{m}^{2} ; \geq 18.5\right.$ and $\left.<25 \mathrm{~kg} / \mathrm{m}^{2} ; \geq 25 \mathrm{~kg} / \mathrm{m}^{2}\right)$, menstrual cycle (regular; irregular; infrequent or none) and amount of menstrual flow (light; average; heavy). Dietary variables were classified by quintile and analysed. In addition, survey year (2006 or 2007), residential block and size of residential area were included as potential confounding factors in the model.

We calculated both crude and multivariate-adjusted odds ratios and 95\% confidence intervals for Fe deficiency for each category of included variables using three logistic regression models. In model 1 , OR were adjusted for survey year, residential block, size of residential area, current smoking status, alcohol drinking status, physical activity, energy intake, BMI, menstrual cycle and Fe intake. In model 2 , they were adjusted for the same factors as in model 1 , including amount of menstrual flow instead of menstrual cycle. In model 3, they were adjusted for the same factors as in model 1 and also amount of menstrual flow. Physical activity, energy intake and BMI were used as continuous variables when they were added as covariates in the models. As results for the crude and multivariate analyses were similar for all variables analysed, we present here only those derived from the multivariate models. Trends of association were examined using a logistic regression model which assigned scores to the level of the independent variable.

All statistical analysis was performed using the SAS statistical software package version 9·1 (SAS Institute Inc., 
Cary, NC, USA). A two-sided $P$ value of $<0.05$ was considered statistically significant.

\section{Results}

Subject characteristics are shown in Table 2. Mean age, total energy and total Fe intake were $19 \cdot 6$ years, $7364 \mathrm{~kJ} / \mathrm{d}$ $(1760 \mathrm{kcal} / \mathrm{d})$ and $3.7 \mathrm{mg} / 4184 \mathrm{~kJ}$, respectively. Mean estimated bioavailable Fe for each body Fe reserve was $0.067 \mathrm{mg} / 4184 \mathrm{~kJ}$ (supposed body Fe reserve $=500 \mathrm{mg}$ ), $0.092 \mathrm{mg} / 4184 \mathrm{~kJ}(250 \mathrm{mg})$ and $0 \cdot 140 \mathrm{mg} / 4184 \mathrm{~kJ}(0 \mathrm{mg})$. A total of $179(17 \cdot 6 \%)$ of 1019 women were classified as having depleted Fe stores and seventy-one $(7 \cdot 0 \%)$ as having Fe deficiency anaemia, giving 250 (24.5\%) women categorized with Fe deficiency.

Table 3 shows the multivariate-adjusted odds ratios and $95 \%$ confidence intervals for Fe deficiency by quintiles of dietary factors. Intakes of total $\mathrm{Fe}$, haem $\mathrm{Fe}$, non-haem $\mathrm{Fe}$ and bioavailable Fe were not significantly associated with Fe deficiency, nor was any association observed for any other dietary factor. Since results for the three multivariate models described in the statistical analysis section were similar for all variables analysed, we present only those derived from model 3 (full model), including both menstrual cycle and amount of menstrual flow, in Table 3.

Table 4 shows the multivariate-adjusted odds ratios and 95\% confidence intervals for Fe deficiency in each category of selected lifestyle factors and health condition. Infrequent menstrual cycles was associated with a decreasing prevalence of $\mathrm{Fe}$ deficiency. In comparison with women categorized as having regular menstrual cycles, the multivariate-adjusted OR $(95 \% \mathrm{CI})$ for women categorized with infrequent or no menstrual cycles was $0.58(0.34,1.00)$ using model 1 . On the other hand, heavy menstrual flow was associated with an increasing prevalence of Fe deficiency. In comparison with women categorized with average flow, the multivariate-adjusted OR (95\% CI) for women in the heavy menstrual flow category was $1 \cdot 83(1 \cdot 35,2 \cdot 48)$ using model 2 and $1 \cdot 85(1 \cdot 36,2 \cdot 51)$ using model 3 . Correspondingly, women with a lighter flow showed a significantly lower prevalence of Fe deficiency in comparison with those with an average flow. No other lifestyle factors or health conditions were associated with the prevalence of $\mathrm{Fe}$ deficiency. These results were not altered if any value for bioavailable Fe intake was included in the model in place of total Fe intake.

\section{Discussion}

In the present study, we found no association between Fe deficiency and a wide range of dietary variables. In contrast, Fe deficiency was associated with menstrual condition, with infrequent menstrual cycles associated with a decreasing prevalence of Fe deficiency while heavy menstrual flow was associated with an increasing prevalence.
Table 2 Characteristics of the subjects: female Japanese dietetic students $(n$ 1019) aged $18-25$ years

\begin{tabular}{|c|c|c|}
\hline Variable & Mean or $n$ & SD or $\%$ \\
\hline Age (years) & $19 \cdot 6$ & $1 \cdot 1$ \\
\hline Body height (cm) & $158 \cdot 3$ & $5 \cdot 5$ \\
\hline Body weight (kg) & 53.6 & $7 \cdot 8$ \\
\hline BMI $\left(\mathrm{kg} / \mathrm{m}^{2}\right)$ & $21 \cdot 4$ & $2 \cdot 8$ \\
\hline \multicolumn{3}{|l|}{ Survey year } \\
\hline 2006 & 417 & $40 \cdot 9$ \\
\hline 2007 & 602 & $59 \cdot 1$ \\
\hline \multicolumn{3}{|l|}{ Residential block } \\
\hline North (Hokkaido, Kanto and Tohoku) & 592 & $58 \cdot 1$ \\
\hline Central (Tokai, Hokuriku and Kinki) & 232 & $22 \cdot 8$ \\
\hline South (Kyushu and Chugoku) & 195 & $19 \cdot 1$ \\
\hline \multicolumn{3}{|l|}{ Size of residential area } \\
\hline City with population $\geq 1$ million & 163 & $16 \cdot 0$ \\
\hline City with population $<1$ million & 791 & $77 \cdot 6$ \\
\hline Town or village & 65 & $6 \cdot 4$ \\
\hline \multicolumn{3}{|l|}{ Current smoking status } \\
\hline No & 995 & $97 \cdot 6$ \\
\hline Yes & 24 & $2 \cdot 4$ \\
\hline \multicolumn{3}{|l|}{ Alcohol drinking status } \\
\hline No & 596 & $58 \cdot 5$ \\
\hline Yes, $<1 \%$ of energy & 247 & $24 \cdot 2$ \\
\hline Yes, $\geq 1 \%$ of energy & 176 & $17 \cdot 3$ \\
\hline Physical activity (MET-h/d) & 33.9 & $3 \cdot 0$ \\
\hline \multicolumn{3}{|l|}{ Menstrual cycle } \\
\hline Regular & 766 & $75 \cdot 2$ \\
\hline Irregular & 148 & $14 \cdot 5$ \\
\hline Infrequent or none & 105 & $10 \cdot 3$ \\
\hline \multicolumn{3}{|l|}{ Amount of menstrual flow } \\
\hline Light & 68 & $6 \cdot 7$ \\
\hline Average & 638 & $62 \cdot 6$ \\
\hline Heavy & 313 & $30 \cdot 7$ \\
\hline \multicolumn{3}{|l|}{ Blood examination } \\
\hline $\mathrm{Hg}(\mathrm{g} / \mathrm{dl})$ & $13 \cdot 4$ & $1 \cdot 0$ \\
\hline Serum Fe $(\mu \mathrm{g} / \mathrm{dl})$ & $96 \cdot 7$ & $41 \cdot 0$ \\
\hline Serum ferritin (ng/ml) & $28 \cdot 2$ & $22 \cdot 8$ \\
\hline \multicolumn{3}{|l|}{ Body Fe status } \\
\hline Normal & 769 & $75 \cdot 5$ \\
\hline Fe deficiency & 250 & $24 \cdot 5$ \\
\hline Depleted Fe stores & 179 & $17 \cdot 6$ \\
\hline $\mathrm{Fe}$ deficiency anaemia & 71 & $7 \cdot 0$ \\
\hline \multicolumn{3}{|l|}{ Dietary intake } \\
\hline Total energy $(\mathrm{kJ} / \mathrm{d})$ & 7364 & 1715 \\
\hline Total energy $(\mathrm{kcal} / \mathrm{d})$ & 1760 & 410 \\
\hline \multicolumn{3}{|l|}{ Nutrient intake } \\
\hline Total Fe (mg/4184kJ) & $3 \cdot 7$ & $0 \cdot 8$ \\
\hline Haem Fe (mg/4184 kJ) & $0 \cdot 24$ & $0 \cdot 12$ \\
\hline Non-haem Fe (mg/4184 kJ) & $3 \cdot 4$ & $0 \cdot 8$ \\
\hline \multicolumn{3}{|l|}{ Bioavailable Fe (mg/4184 kJ) } \\
\hline Body $\mathrm{Fe}$ reserve $=500 \mathrm{mg}$ & 0.067 & 0.026 \\
\hline Body $\mathrm{Fe}$ reserve $=250 \mathrm{mg}$ & 0.092 & 0.035 \\
\hline Body $\mathrm{Fe}$ reserve $=0 \mathrm{mg}$ & $0 \cdot 14$ & 0.05 \\
\hline Phytate $(\mathrm{mg} / 4184 \mathrm{~kJ})$ & $341 \cdot 6$ & $166 \cdot 6$ \\
\hline Vitamin C (mg/4184 kJ) & $47 \cdot 3$ & $21 \cdot 6$ \\
\hline $\mathrm{Ca}(\mathrm{mg} / 4184 \mathrm{~kJ})$ & 283 & $95 \cdot 4$ \\
\hline \multicolumn{3}{|l|}{ Food group intake } \\
\hline Meat $(\mathrm{g} / 4184 \mathrm{~kJ})$ & $33 \cdot 6$ & $16 \cdot 2$ \\
\hline Fish $(\mathrm{g} / 4184 \mathrm{~kJ})$ & $28 \cdot 4$ & $15 \cdot 2$ \\
\hline Cereal (g/4184 kJ) & 222 & $57 \cdot 5$ \\
\hline Dairy products (g/4184 kJ) & $83 \cdot 0$ & $71 \cdot 7$ \\
\hline
\end{tabular}

MET, metabolic equivalent.

Overall prevalence of Fe deficiency in the study was 24.5\% (depleted Fe stores, 17.6\%; Fe deficiency anaemia, $7 \cdot 0 \%$ ). Given the prevalence ratios in a previous study in Japanese women aged $11-90$ years of $41 \cdot 4 \%$ for depleted 
Table 3 Multivariate-adjusted odds ratios and $95 \%$ confidence intervals for iron deficiency by quintile of intake of energy, nutrients and food groups among 1019 Japanese women aged 18-25 years

\begin{tabular}{|c|c|c|c|c|c|c|}
\hline \multirow[b]{3}{*}{ Energy intake $(\mathrm{kJ} / \mathrm{d})$} & \multicolumn{2}{|c|}{ Intake } & \multirow{2}{*}{$\begin{array}{l}n \text { with/without } \\
\text { Fe deficiency }\end{array}$} & \multirow{2}{*}{\multicolumn{2}{|c|}{ Adjusted OR* }} & \multirow[b]{2}{*}{$95 \% \mathrm{Cl}$} \\
\hline & Median & Range & & & & \\
\hline & & & & & & \\
\hline Q1 (Low) & 5343 & $4201-5895$ & $47 / 156$ & 1.00 & & \\
\hline Q2 & 6326 & $5899-6728$ & $55 / 149$ & $1 \cdot 36$ & & $0 \cdot 86,2 \cdot 17$ \\
\hline Q3 & 7155 & $6728-7577$ & $53 / 151$ & $1 \cdot 38$ & & $0 \cdot 86,2 \cdot 21$ \\
\hline Q4 & 8134 & $7581-8644$ & $40 / 164$ & 0.91 & & $0.55,1.50$ \\
\hline Q5 (High) & 9606 & $8648-1456$ & $55 / 149$ & $1 \cdot 47$ & & $0.91,2.37$ \\
\hline$P$ for trend & & & & & $0 \cdot 48$ & \\
\hline \multicolumn{7}{|l|}{ Nutrient intake } \\
\hline \multicolumn{7}{|l|}{ Total Fe $(\mathrm{mg} / 4184 \mathrm{~kJ})$} \\
\hline Q1 & $2 \cdot 8$ & $1 \cdot 8-3 \cdot 1$ & $54 / 149$ & $1 \cdot 00$ & & \\
\hline Q2 & $3 \cdot 3$ & $3 \cdot 1-3 \cdot 4$ & $47 / 157$ & 0.80 & & $0.50,1 \cdot 27$ \\
\hline Q3 & $3 \cdot 6$ & $3 \cdot 4-3 \cdot 8$ & $52 / 152$ & 0.95 & & $0.60,1.51$ \\
\hline Q4 & $4 \cdot 0$ & $3 \cdot 8-4 \cdot 3$ & 49/155 & $0 \cdot 86$ & & $0 \cdot 54,1 \cdot 38$ \\
\hline Q5 & $4 \cdot 7$ & $4 \cdot 3-8 \cdot 3$ & $48 / 156$ & $0 \cdot 86$ & & $0.54,1.38$ \\
\hline$P$ for trend & & & & & $0 \cdot 68$ & \\
\hline \multicolumn{7}{|l|}{ Haem Fe (mg/4184 kJ) } \\
\hline Q1 & $0 \cdot 12$ & $0.03-0.15$ & $48 / 155$ & $1 \cdot 00$ & & \\
\hline Q2 & $0 \cdot 18$ & $0 \cdot 15-0 \cdot 20$ & $53 / 151$ & $1 \cdot 20$ & & $0.75,1.90$ \\
\hline Q3 & 0.23 & $0.20-0.25$ & $49 / 155$ & 0.99 & & $0.62,1.58$ \\
\hline Q4 & 0.28 & $0.25-0.32$ & $50 / 154$ & $1 \cdot 10$ & & $0.69,1.77$ \\
\hline Q5 & 0.38 & $0.32-1.94$ & $50 / 154$ & 0.99 & & $0.62,1.60$ \\
\hline$P$ for trend & & & & & $0 \cdot 86$ & \\
\hline \multicolumn{7}{|l|}{ Non-haem Fe (mg/4184 kJ) } \\
\hline Q1 & $2 \cdot 6$ & $1 \cdot 7-2 \cdot 8$ & $55 / 148$ & $1 \cdot 00$ & & \\
\hline Q2 & $3 \cdot 0$ & $2 \cdot 8-3 \cdot 2$ & $49 / 155$ & $0 \cdot 86$ & & $0 \cdot 54,1 \cdot 36$ \\
\hline Q3 & $3 \cdot 4$ & $3 \cdot 2-3 \cdot 6$ & $47 / 157$ & 0.82 & & $0.51,1.30$ \\
\hline Q4 & $3 \cdot 8$ & $3 \cdot 6-4 \cdot 0$ & $55 / 149$ & $1 \cdot 04$ & & $0.66,1.65$ \\
\hline Q5 & $4 \cdot 4$ & $4 \cdot 0-6 \cdot 8$ & $44 / 160$ & $0 \cdot 77$ & & $0.48,1.23$ \\
\hline$P$ for trend & & & & & 0.54 & \\
\hline Bioavailable Fe (mg/4184 kJ) & $(\mathrm{BIR}=500 \mathrm{mg})$ & & & & & \\
\hline Q1 & 0.043 & $0.027-0.049$ & $52 / 151$ & $1 \cdot 00$ & & \\
\hline Q2 & 0.053 & $0.049-0.056$ & 49/155 & 0.90 & & $0.57,1.44$ \\
\hline Q3 & 0.060 & $0.056-0.065$ & $57 / 157$ & $0 \cdot 87$ & & $0.55,1.39$ \\
\hline Q4 & 0.071 & $0.065-0.080$ & 49/155 & 0.90 & & $0.56,1.43$ \\
\hline Q5 & $0 \cdot 101$ & $0.080-0.276$ & $53 / 151$ & 0.97 & & $0.60,1.55$ \\
\hline$P$ for trend & & & & & $0 \cdot 88$ & \\
\hline Bioavailable Fe (mg/4184 kJ) & $(B I R=250 \mathrm{mg})$ & & & & & \\
\hline Q1 & 0.060 & $0.038-0.067$ & $52 / 151$ & $1 \cdot 00$ & & \\
\hline Q2 & 0.072 & $0.067-0.077$ & $50 / 154$ & 0.93 & & $0.58,1.47$ \\
\hline Q3 & 0.082 & $0.078-0.088$ & $46 / 158$ & $0 \cdot 86$ & & $0.54,1.38$ \\
\hline Q4 & 0.097 & $0.088-0.109$ & $51 / 153$ & 0.96 & & $0.60,1.53$ \\
\hline Q5 & $0 \cdot 139$ & $0 \cdot 109-0 \cdot 350$ & $51 / 153$ & 0.91 & & $0.56,1.47$ \\
\hline$P$ for trend & & & & & $0 \cdot 78$ & \\
\hline Bioavailable Fe (mg/4184 kJ) & $(\mathrm{BIR}=0 \mathrm{mg})$ & & & & & \\
\hline Q1 & 0.092 & $0.058-0.102$ & $52 / 151$ & $1 \cdot 00$ & & \\
\hline Q2 & $0 \cdot 109$ & $0 \cdot 102-0 \cdot 115$ & $50 / 154$ & 0.92 & & $0.58,1.46$ \\
\hline Q3 & $0 \cdot 122$ & $0 \cdot 116-0 \cdot 130$ & $42 / 162$ & $0 \cdot 78$ & & $0 \cdot 49,1 \cdot 27$ \\
\hline Q4 & $0 \cdot 141$ & $0 \cdot 130-0 \cdot 160$ & $53 / 151$ & 1.00 & & $0.63,1.59$ \\
\hline Q5 & $0 \cdot 208$ & $0.160-0.471$ & $53 / 151$ & 0.96 & & $0.59,1.56$ \\
\hline$P$ for trend & & & & & 0.99 & \\
\hline \multicolumn{7}{|l|}{ Phytate (mg/4184 kJ) } \\
\hline Q1 & $183 \cdot 2$ & $84 \cdot 6-212 \cdot 6$ & $53 / 150$ & $1 \cdot 00$ & & \\
\hline Q2 & $239 \cdot 4$ & $212 \cdot 9-269 \cdot 3$ & $52 / 152$ & 0.95 & & $0 \cdot 60,1 \cdot 50$ \\
\hline Q3 & $301 \cdot 8$ & $269 \cdot 3-332 \cdot 5$ & $46 / 158$ & $0 \cdot 86$ & & $0.53,1.39$ \\
\hline Q4 & $372 \cdot 7$ & $332 \cdot 8-438 \cdot 5$ & $51 / 153$ & 0.93 & & $0.57,1.51$ \\
\hline Q5 & $562 \cdot 2$ & $439 \cdot 2-1368 \cdot 8$ & $48 / 156$ & 0.86 & & $0.51,1.47$ \\
\hline$P$ for trend & & & & & $0 \cdot 62$ & \\
\hline \multicolumn{7}{|l|}{ Vitamin C (mg/4184 kJ) } \\
\hline Q1 & $25 \cdot 4$ & $6 \cdot 9-30 \cdot 8$ & $53 / 150$ & $1 \cdot 00$ & & \\
\hline Q2 & $35 \cdot 3$ & $30 \cdot 8-39 \cdot 0$ & $49 / 155$ & 0.84 & & $0.53,1 \cdot 34$ \\
\hline Q3 & $43 \cdot 2$ & $39 \cdot 1-48 \cdot 2$ & $44 / 160$ & 0.79 & & $0.48,1.28$ \\
\hline Q4 & $53 \cdot 0$ & $48 \cdot 2-60 \cdot 8$ & $67 / 137$ & $1 \cdot 39$ & & $0 \cdot 85,2 \cdot 27$ \\
\hline Q5 & $75 \cdot 2$ & $60 \cdot 8-202 \cdot 0$ & $37 / 167$ & 0.61 & & $0.35,1.05$ \\
\hline$P$ for trend & & & & & 0.46 & \\
\hline $\mathrm{Ca}(\mathrm{mg} / 4184 \mathrm{~kJ})$ & & & & & & \\
\hline Q1 & 175 & 104-202 & $54 / 149$ & $1 \cdot 00$ & & \\
\hline Q2 & 224 & $202-248$ & 49/155 & 0.90 & & $0.56,1 \cdot 46$ \\
\hline
\end{tabular}




\begin{tabular}{|c|c|c|c|c|c|}
\hline & \multicolumn{2}{|c|}{ Intake } & \multirow{2}{*}{$\begin{array}{l}n \text { with/without } \\
\text { Fe deficiency }\end{array}$} & \multirow[b]{2}{*}{ Adjusted OR* } & \multirow[b]{2}{*}{$95 \% \mathrm{Cl}$} \\
\hline & Median & Range & & & \\
\hline Q3 & 268 & 248-290 & $57 / 147$ & $1 \cdot 20$ & $0.74,1.94$ \\
\hline Q4 & 318 & $290-352$ & $45 / 159$ & 0.88 & $0.53,1.47$ \\
\hline Q5 & 414 & $352-699$ & $45 / 159$ & 0.89 & $0.53,1.48$ \\
\hline$P$ for trend & & & & & \\
\hline \multicolumn{6}{|c|}{ Food group intake } \\
\hline \multicolumn{6}{|c|}{ Meat (g/4184 kJ) } \\
\hline Q1 & $16 \cdot 0$ & $3 \cdot 4-20 \cdot 1$ & $52 / 151$ & $1 \cdot 00$ & \\
\hline Q2 & $23 \cdot 7$ & $20 \cdot 2-27 \cdot 3$ & $54 / 150$ & 1.03 & $0.65,1.62$ \\
\hline Q3 & $30 \cdot 9$ & $27 \cdot 3-35 \cdot 2$ & $48 / 156$ & 0.77 & $0.48,1.23$ \\
\hline Q4 & $40 \cdot 0$ & $35 \cdot 2-44 \cdot 9$ & $50 / 154$ & 0.90 & $0.56,1.43$ \\
\hline Q5 & $54 \cdot 0$ & $45 \cdot 0-135 \cdot 0$ & $46 / 158$ & 0.73 & $0 \cdot 45,1 \cdot 18$ \\
\hline$P$ for trend & & & & & \\
\hline \multicolumn{6}{|c|}{ Fish $(\mathrm{g} / 4184 \mathrm{~kJ})$} \\
\hline Q1 & $11 \cdot 6$ & $0 \cdot 0-15 \cdot 8$ & $50 / 153$ & $1 \cdot 00$ & \\
\hline Q2 & $19 \cdot 8$ & $15 \cdot 8-22 \cdot 9$ & $55 / 149$ & $1 \cdot 20$ & $0.76,1.91$ \\
\hline Q3 & $25 \cdot 8$ & $22 \cdot 9-29 \cdot 8$ & $44 / 160$ & 0.89 & $0.55,1.44$ \\
\hline Q4 & $33 \cdot 7$ & $29 \cdot 8-38 \cdot 7$ & $51 / 153$ & $1 \cdot 12$ & $0 \cdot 70,1 \cdot 81$ \\
\hline Q5 & $48 \cdot 0$ & $38 \cdot 7-111 \cdot 0$ & $50 / 154$ & $1 \cdot 02$ & $0.62,1.67$ \\
\hline$P$ for trend & & & & & \\
\hline \multicolumn{6}{|c|}{ Cereals (g/4184 kJ) } \\
\hline Q1 & 152 & $41-174$ & $49 / 154$ & $1 \cdot 00$ & \\
\hline Q2 & 189 & $174-205$ & $45 / 159$ & $0 \cdot 89$ & $0.55,1.44$ \\
\hline Q3 & 221 & $205-234$ & $47 / 157$ & 0.91 & $0.56,1.48$ \\
\hline Q4 & 250 & $234-268$ & $57 / 147$ & $1 \cdot 16$ & $0.71,1.89$ \\
\hline Q5 & 298 & $268-425$ & $52 / 152$ & 0.90 & $0.53,1.52$ \\
\hline$P$ for trend & & & & & \\
\hline \multicolumn{6}{|c|}{ Dairy products $(\mathrm{g} / 4184 \mathrm{~kJ})$} \\
\hline Q1 & $12 \cdot 6$ & $0-21 \cdot 6$ & $56 / 147$ & $1 \cdot 00$ & \\
\hline Q2 & $36 \cdot 4$ & $21 \cdot 7-49 \cdot 5$ & $49 / 155$ & 0.83 & $0.53,1.31$ \\
\hline Q3 & $65 \cdot 8$ & $49 \cdot 9-82 \cdot 4$ & $44 / 160$ & 0.76 & $0.48,1 \cdot 22$ \\
\hline Q4 & $102 \cdot 0$ & $82 \cdot 5-125 \cdot 0$ & $51 / 153$ & 0.97 & $0.61,1.54$ \\
\hline Q5 & $182 \cdot 0$ & $125 \cdot 0-367 \cdot 0$ & $50 / 154$ & 0.92 & $0.58,1.47$ \\
\hline$P$ for trend & & & & & \\
\hline
\end{tabular}

Q, quintile. BIR, body Fe reserve.

*Adjusted OR: adjusted for survey year (2006 or 2007), residential block (north, Hokkaido, Kanto and Tohoku; central, Tokai, Hokuriku and Kinki; south, Kyushu and Chugoku), size of residential area (city with population $\geqslant 1$ million; city with population $<1$ million; town or village), current smoking status, alcohol drinking status, physical activity (total MET-h/d, continuous; where MET = metabolic equivalent), energy intake (kJ/d, continuous), BMI (kg/m², continuous), menstrual cycle, amount of menstrual flow and Fe intake (mg/4184 kJ, quintiles). Nutrients and food groups other than total Fe were substituted singly.

Nutrients and food groups that were analysed but found not to be related with Fe deficiency were total Fe, haem Fe, non-haem Fe, bioavailable Fe, phytate, vitamin $\mathrm{C}, \mathrm{Ca}$, protein, carbohydrate, fat, total dietary fibre, vitamin $\mathrm{A}$, vitamin $\mathrm{D}, \alpha$-tocopherol, vitamin $\mathrm{B}_{12}$, folic acid, meat, fish, cereals, dairy products, green vegetables, other vegetables, pulses, potatoes, nuts, fruits, eggs, black tea and coffee.

Fe stores and $8.5 \%$ for Fe deficiency anaemia ${ }^{(3)}$, our present ratios are relatively low. However, these results should be interpreted carefully, as all subjects were volunteer dietetic students who may have led a relatively healthy lifestyle. On the other hand, mean Fe intake among our subjects was a relatively low, $3 \cdot 70 \mathrm{mg} / 4184 \mathrm{~kJ}$ with energy adjustment or $6.55 \mathrm{mg} / \mathrm{d}$ without. The lower mean Fe intake in Japan than in other developed countries ${ }^{(19-22)}$ is likely attributed to the different dietary habits of most Japanese, with greater consumption of rice and fish and lower consumption of meat ${ }^{(23)}$. This difference in Japanese dietary habits also likely influenced bioavailable Fe levels in our study.

Dietary factors known to enhance Fe absorption are ascorbic acid (vitamin C), animal tissues (such as meat, fish and poultry), organic acids (such as citric acid and lactic acid), fermented soya products, cysteine-containing peptides $^{(2)}$ and vitamin $\mathrm{A}^{(46)}$. When present in sufficient quantity, ascorbic acid has been reported to enhance non- haem Fe absorption in a dose-dependent manner, owing to its ability to overcome the inhibitory effect of phytate ${ }^{(47)}$. Animal tissues, especially red meat such as beef, pork and lamb, not only enhance Fe absorption, but are also excellent sources of highly bioavailable haem $\mathrm{Fe}^{(48)}$. In contrast, phytate, polyphenols, Ca, dairy products, soya proteins and dietary fibres are known to inhibit non-haem Fe absorption $^{(2,9)}$. We estimated phytate intake values in the present study and found them to be compatible with those previously reported $^{(37,39)}$. Nevertheless, a food composition table describing phytate content in Japanese food is not available, and further studies are needed to confirm phytate intake in the Japanese population. Phytate intake is also essential to the estimation of bioavailable Fe intake, and measurement of phytate content in Japanese food is therefore also necessary to clarify bioavailable Fe intake in Japan.

To estimate bioavailable Fe intake, we used the algorithms developed by Bhargava et al. ${ }^{(37)}$ because these 
Table 4 Multivariate-adjusted odds ratios and $95 \%$ confidence intervals for iron deficiency in relation to selected lifestyle factors and health conditions among 1019 Japanese women aged 18-25 years

\begin{tabular}{|c|c|c|c|c|c|c|c|c|c|}
\hline & \multicolumn{2}{|c|}{ Value } & \multirow{2}{*}{$\begin{array}{l}n \text { with/without } \\
\text { Fe deficiency }\end{array}$} & \multicolumn{2}{|c|}{ Model 1* } & \multicolumn{2}{|c|}{ Model 2† } & \multicolumn{2}{|c|}{ Model 3‡ } \\
\hline & Median & Range & & OR & $95 \% \mathrm{Cl}$ & OR & $95 \% \mathrm{Cl}$ & OR & $95 \% \mathrm{Cl}$ \\
\hline \multicolumn{10}{|l|}{ Current smoking status } \\
\hline No & & & $241 / 754$ & 1.00 & & $1 \cdot 00$ & & 1.00 & \\
\hline Yes & & & 9/15 & $1 \cdot 68$ & $0 \cdot 69,4.07$ & $1 \cdot 47$ & $0.60,3.59$ & $1 \cdot 41$ & $0.57,3.44$ \\
\hline$P$ & & & & 0.25 & & $0 \cdot 40$ & & 0.46 & \\
\hline \multicolumn{10}{|l|}{ Alcohol drinking status } \\
\hline No & & & $149 / 447$ & $1 \cdot 00$ & & $1 \cdot 00$ & & $1 \cdot 00$ & \\
\hline Yes, $<1 \%$ of energy & & & $60 / 187$ & 0.94 & $0 \cdot 66,1 \cdot 33$ & 0.95 & $0.67,1.36$ & 0.94 & $0 \cdot 66,1 \cdot 34$ \\
\hline Yes, $\geq 1 \%$ of energy & & & $41 / 135$ & $0 \cdot 85$ & $0 \cdot 56,1 \cdot 29$ & $0 \cdot 84$ & $0 \cdot 55,1 \cdot 28$ & $0 \cdot 84$ & $0.55,1.29$ \\
\hline$P$ for trend $\S$ & & & & 0.43 & & $0 \cdot 42$ & & $0 \cdot 42$ & \\
\hline \multicolumn{10}{|l|}{ Physical activityll } \\
\hline Low & $32 \cdot 0$ & $29 \cdot 3-32 \cdot 6$ & $82 / 255$ & $1 \cdot 00$ & & $1 \cdot 00$ & & $1 \cdot 00$ & \\
\hline Middle & $33 \cdot 2$ & $32 \cdot 6-33 \cdot 9$ & $86 / 256$ & $1 \cdot 11$ & $0.77,1.58$ & $1 \cdot 11$ & $0.77,1.59$ & $1 \cdot 12$ & $0.78,1.61$ \\
\hline High & $35 \cdot 3$ & $33 \cdot 9-68 \cdot 6$ & $82 / 258$ & 1.05 & $0 \cdot 73,1 \cdot 51$ & 1.03 & $0 \cdot 71,1 \cdot 50$ & 1.05 & $0.72,1.51$ \\
\hline$P$ for trend & & & & 0.79 & & 0.86 & & 0.82 & \\
\hline \multicolumn{10}{|l|}{ Menstrual cycle } \\
\hline Regular & & & 199/567 & $1 \cdot 00$ & & - & & $1 \cdot 00$ & \\
\hline Irregular & & & $33 / 115$ & $0 \cdot 84$ & $0 \cdot 55,1 \cdot 28$ & - & & $0 \cdot 88$ & $0.58,1.36$ \\
\hline Infrequent or none & & & $18 / 87$ & 0.58 & $0 \cdot 34,1 \cdot 00$ & - & & $0 \cdot 69$ & $0 \cdot 39,1 \cdot 22$ \\
\hline$P$ for trend & & & & 0.04 & & & & $0 \cdot 18$ & \\
\hline \multicolumn{10}{|l|}{ Amount of menstrual flow } \\
\hline Light & & & $5 / 63$ & - & & $0 \cdot 28$ & $0 \cdot 11,0 \cdot 71$ & $0 \cdot 32$ & $0 \cdot 12,0 \cdot 82$ \\
\hline Average & & & $139 / 499$ & - & & $1 \cdot 00$ & & $1 \cdot 00$ & \\
\hline Heavy & & & $106 / 207$ & - & & $1 \cdot 83$ & $1 \cdot 35,2 \cdot 48$ & $1 \cdot 85$ & $1 \cdot 36,2 \cdot 51$ \\
\hline$P$ for trend & & & & & & $<0.0001$ & & $<0.0001$ & \\
\hline \multicolumn{10}{|l|}{ BMI $\left(\mathrm{kg} / \mathrm{m}^{2}\right)$ ฯ } \\
\hline$<18 \cdot 5$ & & & 22/89 & $0 \cdot 71$ & $0 \cdot 43,1 \cdot 17$ & $0 \cdot 75$ & $0 \cdot 45,1 \cdot 25$ & $0 \cdot 76$ & $0.45,1.25$ \\
\hline$\geq 18 \cdot 5,<25$ & & & $212 / 608$ & $1 \cdot 00$ & & 1.00 & & 1.00 & \\
\hline$\geq 25$ & & & 16/72 & 0.59 & $0 \cdot 33,1 \cdot 04$ & 0.57 & $0 \cdot 32,1 \cdot 01$ & 0.55 & $0.31,0.99$ \\
\hline$P$ for trend & & & & $0 \cdot 77$ & & 0.56 & & 0.52 & \\
\hline
\end{tabular}

*Model 1: adjusted for survey year (2006 or 2007), residential block (north, Hokkaido, Kanto and Tohoku; central, Tokai, Hokuriku and Kinki; south, (Kyushu and Chugoku), size of residential area (city with population $\geq 1$ million; city with population $<1$ million; town or village), current smoking status, alcohol drinking status, physical activity (total MET-h/d, continuous; where MET = metabolic equivalent), energy intake (kJ/d, continuous), BMI (kg/m² ${ }^{2}$ continuous), menstrual cycle and total Fe intake (mg/4184 kJ, quintiles).

+Model 2: adjusted for the same factors as model 1, including amount of menstrual flow instead of menstrual cycle.

¥Model 3: adjusted for the same factors as model 1 and amount of menstrual flow.

\$Trend of association was examined by a logistic regression model assigning scores to the levels of the independent variable.

IIPhysical activity was divided into three groups by tertiles, and odds ratios were calculated by using groups of physical activity as a categorical variable in the models.

- BMI was divided into three groups at values of 18.5 and $25 \mathrm{~kg} / \mathrm{m}^{2}$, and odds ratios were calculated by using groups by BMI as a categorical variable in the models.

algorithms were established for Bangladeshi subjects who mainly consume rice and do not eat so much animal products. Also, the algorithms were thought to be suitable for our available data because we did not have enough information about polyphenols and tea except black tea, which is needed to use the Hallberg or Tseng algorithms.

We examined all of the dietary factors known to affect Fe metabolism except organic acids, fermented soya products and cysteine-containing peptides. However, results showed no significant association between body Fe status and any dietary factor including total Fe, haem Fe, non-haem Fe and bioavailable Fe. Although our sample size was relatively small and subject characteristics were relatively uniform, the range of $\mathrm{Fe}$ intake of 2.50 to $20.01 \mathrm{mg} / \mathrm{d}$ suggested a sufficient dispersion of Fe intake.

With regard to the influence of menstruation, results suggested the presence of a dose-response relationship between the amount of menstrual flow and the prevalence of Fe deficiency, albeit that assessment of menstruation was based strictly on unguided self-reporting. These results are consistent with those of previous studies $^{(14,49)}$ and clearly are plausible. Menstrual loss of $\mathrm{Fe}$ is the main source of variation in the Fe requirements of non-pregnant, menstruating women and higher menstrual blood loss is associated with a higher prevalence of Fe deficiency ${ }^{(14,15)}$. Furthermore, several studies have reported a significant inverse correlation between $\mathrm{Fe}$ stores and the duration of menstruation ${ }^{(49-51)}$. In addition, a number of studies in European women have shown a skewed distribution in menstrual blood losses ${ }^{(49,52-54)}$ : while median menstrual loss was about $30 \mathrm{ml}$, equivalent to a daily Fe loss of $0.45 \mathrm{mg}, 25 \%$ had a loss exceeding $0.85 \mathrm{mg} / \mathrm{d}$ and $5 \%$ had a loss exceeding $1.75 \mathrm{mg} / \mathrm{d}$. It is suggested that a fraction of women have Fe requirements substantially above mean values.

It might be interesting to explore the relationship between hormonal contraceptive use and Fe deficiency, because usage of hormonal contraceptives clearly affects menstruation. However, it was reported that only $1 \cdot 1 \%$ of Japanese women of reproductive age (15-49 years) are using them ${ }^{(55)}$. Therefore we did not include the contraceptive method in our model. 
Other lifestyle factors, including current smoking status, alcohol drinking status and physical activity level, as well as BMI, were not associated with the prevalence of Fe deficiency. However, several important factors not considered in the study are likely relevant. For example, body Fe status may be affected by several genetic variations. Although no genetic syndrome in man causing isolated Fe deficiency has been described, differences in response to Fe-deficient diets in genetically distinct mice have been observed $^{(56)}$. Several case reports have described familial Fe deficiency anaemia that is unresponsive to oral Fe therapy and incompletely responsive to parenteral Fe therapy ${ }^{(57-59)}$. Further, mutation of the hereditary haemochromatosis (HEF) gene is well-known as the most common cause of hereditary haemochromatosis ${ }^{(60,61)}$.

Several limitations of the present study warrant mention. First, although Fe deficiency has been widely studied, definitions of Fe deficiency, depleted Fe stores and Fe deficiency anaemia have not been properly established. We based our diagnosis of Fe deficiency on previously reported values for $\mathrm{Hb}$ concentration and serum ferritin level ${ }^{(42,43)}$. Nevertheless, concerns about the use of serum ferritin level as an index of body Fe status have been expressed; among them, serum ferritin escalation can coincide with minor infection that is not related to levels of Fe stores ${ }^{(62)}$ and day-to-day variability may be subject to measurement imprecision ${ }^{(63,64)}$.

Given these concerns, several studies have used transferrin saturation (the value of serum Fe/total Fe binding capacity $\times 100(\%))$ in combination with $\mathrm{Hb}$ concentration and serum ferritin level as an index of Fe deficiency $^{(42,43,65)}$. Generally, Fe deficiency is diagnosed when transferrin saturation is below $16 \%$. However, transferrin saturation similarly decreases with mild or transient infection and shows wide diurnal variation in normal individuals ${ }^{(42)}$. Given that our present subjects were young and assumed to be generally healthy, we considered that the presence of infection would be less likely. To simplify diagnostic criteria, we therefore restricted the indices to serum ferritin level and $\mathrm{Hb}$ concentration.

Second, although the DHQ used has been validated with respect to commonly studied nutritional factors, including $\mathrm{Fe}$, as described above, the validity of several factors used in the present study, including bioavailable Fe and phytate, is unknown. The results should thus be interpreted with caution. Additionally, it is true that misreporting is one of the major limitations of any self-reported dietary assessment method. However, the reporting accuracy of the subjects was thought to be acceptable according to a previous study(66) which included the same subjects as the present study. In the present study, reporting accuracy was calculated as the ratio of reported dietary intake obtained from the DHQ to estimated dietary intake obtained from respective biological markers, and most of the calculated values were in the range of $0 \cdot 9-1 \cdot 2$. For the analysis of our study, nutrient and food intakes were energy-adjusted to avoid the effect of misreporting.

Finally, the present study was a cross-sectional study and thus susceptible to the possibility of reverse causality. Namely, subjects who were conscious of their own Fe deficiency might have increased their consumption of Fe-rich foods. We therefore excluded from analysis those subjects taking Fe supplements, but included two subjects using Fe preparations as therapy for anaemia as patients with Fe deficiency anaemia without regard to $\mathrm{Hb}$ or serum ferritin values.

In conclusion, we found no association between any dietary habit, including $\mathrm{Fe}$ intake, and Fe deficiency. In contrast, the only variables showing a statistically significant association with the prevalence of Fe deficiency were related with menstrual condition, i.e. menstrual cycle regularity and amount of menstrual flow.

\section{Acknowledgements}

Source of funding: This work was supported by grants from the Japanese Ministry of Health, Labour and Welfare.

Conflict of interest declaration: None of the authors has any conflict of interest to declare.

Authorship responsibilities: K.A. was involved in designing the study, conducted the statistical analysis and wrote the manuscript. S.S. was responsible for designing the study, data collection and data management, the overall management, and assisted in manuscript preparation. K.M. coordinated the field work, was involved in designing the study, data collection and data management, and assisted in manuscript preparation. Y.T. and K.U. were involved in study design, data collection and data management. M.Y. was involved in study design and assisted in statistical analysis. Y.N., Y.K. and T.T were involved in study design and assisted in manuscript preparation. All of the authors provided suggestions during the preparation of the manuscript and approved the final version submitted for publication.

\section{References}

1. Looker AC, Dallman PR, Carroll MD, Gunter EW \& Johnson CL (1997) Prevalence of iron deficiency in the United States. JAMA 277, 973-976.

2. Heath A-LM \& Fairweather-Tait SJ (2002) Clinical implications of changes in the modern diet: iron intake, absorption and status. Best Pract Res Clin Haematol 15, 225-241.

3. Uchida T, Kawachi Y, Sakamoto Y, Igaki T, Ogasawara N, Kariyone S, Matsuda S, Tanaka T, Kimura H \& Kokubun K (1992) Prevalence and pathogenesis of iron deficiency in Japanese women (1981-1991). Rinsho Ketsueki 33, 1661-1665.

4. Sanstead HH (2000) Causes of iron and zinc deficiencies and their effects on brain. $J$ Nutr 130, 347S-349S.

5. Scholz B, Gross R, Schultink W \& Sastroamidjojo S (1997) Anaemia is associated with reduced productivity of women 
workers even in less-physically-strenuous tasks. Br J Nutr 77, 47-57.

6. Scrimshaw N (1991) Iron deficiency. Sci Am 265, 46-52.

7. Brabin BJ, Hakimi M \& Pelletier D (2001) An analysis of anemia and pregnancy-related maternal mortality. J Nutr 131, 604S-614S.

8. Scholl TO \& Reilly T (2000) Anemia, iron and pregnancy outcome. J Nutr 130, 443S-447S.

9. Galan P, Yoon H-C, Preziosi P et al. (1998) Determining factors in the iron status of adult women in the SU. VI.MAX study. Eur J Clin Nutr 52, 383-388.

10. Deegan H, Bates HM \& McCargar LJ (2005) Assessment of iron status in adolescents: dietary, biochemical and lifestyle determinants. J Adolesc Health 37, 75.e15-75.e21.

11. Cade JE, Moreton JA, O'Hara B, Greenwood DC, Moor J, Burley VJ, Kukalizch K, Bishop DT \& Worwood M (2005) Diet and genetic factors associated with iron status in middle-aged women. Am J Clin Nutr 82, 813-820.

12. Pynaert I, Delanghe J, Temmerman M \& De Henauw S (2007) Iron intake in relation to diet and iron status of young adult women. Ann Nutr Metab 51, 172-181.

13. Suedekum NA \& Dimeff RJ (2005) Iron and the athlete. Curr Sports Med Rep 4, 199-202.

14. Harvey LJ, Armah CN, Dainty JR, Foxall RJ, Lewis DJ, Langford NJ \& Fairweather-Tait SJ (2005) Impact of menstrual blood loss and diet on iron deficiency among women in the UK. Br J Nutr 94, 557-564.

15. Heath A-LM, Skeaff CM, Williams S \& Gibson RS (2001) The role of blood loss and diet in the aetiology of mild iron deficiency in premenopausal adult New Zealand women. Public Health Nutr 4, 197-206.

16. Barr F, Brabin L, Agbaje S, Buseri F, Ikimalo J \& Brigg N (1998) Reducing iron deficiency anaemia due to heavy menstrual blood loss in Nigerian rural adolescents. Public Health Nutr 1, 249-257.

17. Foo LH, Khor GL, Tee E-S \& Dhanaraj P (2004) Determinants of iron status in Malaysian adolescents from a rural community. Int J Food Sci Nutr 55, 517-525.

18. Thankachan P, Muthayya S, Walczyk T, Kurpad AV \& Hurrell RF (2007) An analysis of the etiology of anemia and iron deficiency in young women of low socioeconomic status in Bangalore, India. Food Nutr Bull 28, 328-336.

19. Park SY, Paik HY, Skinner JD, Spindler AA \& Park HR (2004) Nutrient intake of Korean-American, Korean, and American adolescents. J Am Diet Assoc 104, 242-245.

20. Pynaert I, Matthys C, Bacquer DD, Backer GD \& Henauw SD (2008) Evaluation of a 2-day food record to determine iron, calcium and vitamin $\mathrm{C}$ intake in young Belgian women. Eur J Clin Nutr 62, 104-110.

21. Vyas A, Greenhalgh A, Cade J, Sanghera B, Riste L, Sharma S \& Cruickshank K (2003) Nutrient intakes of an adult Pakistani, European and African-Caribbean community in inner city Britain. J Hum Nutr Diet 16, 327-337.

22. Matsuda-Inoguchi N, Shimbo S, Nakatsuka H, Watanabe T, Higashioka K \& Ikeda M (2004) Effects of revision of Japanese food composition tables on estimation of nutrient intakes, with reference to age-dependent differences. Public Health Nutr 7, 901-909.

23. Tsugane S, Sasaki S, Kobayashi M, Tsubono Y \& Sobue T (2001) Dietary habits among the JPHC study participants at baseline survey. Japan Public Health Center-based Prospective Study on Cancer and Cardiovascular Diseases. J Epidemiol 11, 6 Suppl., S30-S43.

24. Yamamoto S, Sobue T, Sasaki S et al. (2001) Validity and reproducibility of a self-administered food-frequency questionnaire to assess isoflavone intake in a Japanese population in comparison with dietary records and blood and urine isoflavones. J Nutr 131, 2741-2747.

25. Tsubono Y, Nishio Y, Komatsu S, Hsieh C-C, Kanemura S, Tsuji I, Nakatsuka H, Fukao A, Satoh H \& Hisamichi S
(2001) Green tea and the risk of gastric cancer in Japan. $N$ Engl J Med 344, 632-636.

26. Sasaki S, Ushio F, Amano K, Morihara M, Todoroki T, Uehara Y \& Toyooka E (2000) Serum biomarker-based validation of a self-administered diet history questionnaire for Japanese subjects. J Nutr Sci Vitaminol 46, 285-296.

27. Sasaki S, Yanagibori R \& Amano K (1998) Self-administered diet history questionnaire developed for health education: a relative validation of the test-version by comparison with 3-day diet record in women. J Epidemiol 8, 203-215.

28. Sasaki S, Yanagibori R \& Amano K (1998) Validity of a selfadministered diet history questionnaire for assessment of sodium and potassium: comparison with single 24-hour urinary excretion. Jpn Circ J 62, 431-435.

29. Murakami K, Sasaki S, Takahashi Y, Okubo H, Hirota N, Notsu A, Fukui M \& Date C (2008) Reproducibility and relative validity of dietary glycaemic index and load assessed with a self-administered diet-history questionnaire in Japanese adults. Br J Nutr 99, 639-648.

30. Science and Technology Agency (2005) Standard Tables of Food Composition in Japan, fifth revised and enlarged ed. Tokyo: Printing Bureau of the Ministry of Finance.

31. Monsen ER, Hallberg L, Layrisee M, Hegsted M, Cook JD, Mertz W \& Finch CA (1978) Estimation of available dietary iron. Am J Clin Nutr 31, 134-141.

32. Harland BF \& Oberleas D (1987) Phytate in foods. World Rev Nutr Diet 52, 235-259.

33. Ma G, Jin Y, Piao J, Kok F, Guusje B \& Jacobsen E (2005) Phytate, calcium, iron and zinc contents and their molar ratios in foods commonly consumed in China. J Agric Food Chem 53, 10285-10290.

34. Wolters MGE, Diepenmaat HB, Hermus RJ \& Voragen AGJ (1993) Relation between in vitro availability of minerals and food composition: a mathematical model. J Food Sci 58, 1349-1355.

35. Khokhar S, Pushpanjali \& Fenwick GR (1994) Phytate content of Indian foods and intakes by vegetarian Indians of Hisar region, Haryana state. J Agric Food Chem 42, 2440-2444.

36. Monsen ER \& Balintfy JL (1982) Calculating dietary iron bioavailability: refinement and computerization. J Am Diet Assoc 80, 307-311.

37. Bhargava A, Bouis HE \& Scrimshaw NS (2001) Dietary intakes and socioeconomic factors are associated with the hemoglobin concentration of Bangladeshi women. J Nutr 131, 758-764.

38. Tseng $M$, Chakraborty $H$, Robinson DT, Mendez M \& Kohlmeier L (1997) Adjustment of iron intake for dietary enhancers and inhibitors in population studies: bioavailable iron in rural and urban residing Russian women and children. J Nutr 127, 1456-1468.

39. Rodriguez SC, Hotz C \& Rivera JA (2007) Bioavailable dietary iron is associated with hemoglobin concentration in Mexican preschool children. J Nutr 137, 2304-2310.

40. Hallberg L \& Hulthen L (2000) Prediction of dietary iron absorption: an algorithm for calculating absorption and bioavailability of dietary iron. Am J Clin Nutr 71, 1147-1160.

41. Zijp IM, Korver O \& Tijburg LBM (2000) Effect of tea and other dietary factors on iron absorption. Crit Rev Food Sci Nutr 40, 371-398.

42. Cook JD \& Finch CA (1979) Assessing iron status of a population. Am J Clin Nutr 32, 2115-2119.

43. Cook JD \& Skikne B (1989) Iron deficiency: definition and diagnosis. J Intern Med 226, 349-355.

44. Ainsworth BE, Haskell WL, Leon AS, Jacobs DR Jr, Montoye HJ, Sallis JF \& Paffenbarger RS Jr (1993) Compendium of physical activities: classification of energy costs of human physical activities. Med Sci Sports Exerc 25, 71-80. 
45. Murakami K, Sasaki S, Takahashi Y, Uenishi K \& the Japan Dietetic Students' Study for Nutrition and Biomarkers Group (2007) Dietary energy density is associated with body mass index and waist circumference, but not with other metabolic risk factors, in free-living young Japanese women. Nutrition 23, 798-806.

46. Layrisse M, Garcia-Casal MN, Solano L, Baron MA, Arguello F, Llovera D, Ramirez J, Leets I \& Tropper E (1997) The role of vitamin A on the inhibitors of nonheme iron absorption: preliminary results. J Nutr Biochem 8, 61-67.

47. Davidsson L, Galan P, Kastenmayer P, Cherouyrier F, Juillerat MA, Serge H \& Hurrell RF (1994) Iron bioavailability studied in infants: the influence of phytic acid and ascorbic acid in infant formulas based on soy isolate. Pediatr Res 36, 816-822.

48. Fleming DJ, Tucker KL, Jacques PF, Dallal GE, Wilson PWF \& Wood RJ (2002) Dietary factors associated with the risk of high iron stores in the elderly Framingham Heart Study cohort. Am J Clin Nutr 76, 1375-1384.

49. Milman N (1996) Serum ferritin in Danes: studies of iron status from infancy to old age, during blood donation and pregnancy. Int J Hematol 63, 103-135.

50. Milman $\mathrm{N}$, Rosdahl N, Lyhne $\mathrm{N} \&$ Jogersen $\mathrm{T}$ (1993) Iron stores in 883 Danish women aged 35-65 years. Relation to menstruation and method for contraception. Acta Obstet Gynecol Scand 72, 601-605.

51. Rangan AM, Aitken I, Blight GD \& Binns CW (1997) Factors affecting iron status in 15-30 year old female students. Asia Pac J Clin Nutr 6, 291-295.

52. Hallberg L, Hogdahl AM, Nilsson L \& Rybo G (1966) Menstrual blood loss - a population study. Variation at different ages and attempts to define mortality. Acta Obstet Gynecol Scand 45, 320-351.

53. Cole SK, Billewicz WZ \& Thomson AM (1971) Sources of variation in menstrual blood loss. J Obstet Gynaecol Br Commonw 78, 933-939.

54. Milman N, Kirchhoff $M$ \& Jogersen $T$ (1992) Iron status markers, serum ferritin and haemoglobin in 1359 Danish women in relation to menstruation, hormonal contraception, parity, and postmenopausal hormone treatment. Ann Hematol 65, 96-102.
55. United Nations Population Division, Department of Economics and Social Affairs (2008) World Contraceptive Use 2007. http://www.un.org/esa/population/publications/ contraceptive2007/contraceptive_2007_table.pdf (accessed October 2008).

56. Morse AC, Beard JL \& Jones BC (1999) A genetic developmental model of iron deficiency: biological aspects. Proc Soc Exp Biol Med 220, 147-152.

57. Buchanan GR \& Sheehan RG (1981) Malabsorption and defective utilization of iron in three siblings. $J$ Pediatr $\mathbf{9 8 ,}$ $723-728$.

58. Hartman KR \& Barker JA (1996) Microcytic anemia with iron malabsorption: an inherited disorder of iron metabolism. Am J Hematol 51, 269-275.

59. Pearson HA \& Lukens JN (1999) Ferrokinetics in the syndrome of familial hypoferremic microcytic anemia with iron malabsorption. J Pediatr Hematol Oncol 21, 412-417.

60. Beutler E, Felitti VJ, Koziol JA, Ho NJ \& Gelbart T (2002) Penetrance of $845 \mathrm{G} \rightarrow \mathrm{A}(\mathrm{C} 282 \mathrm{Y})$ HFE hereditary haemochromatosis mutation in the USA. Lancet 359, 211-218.

61. McCune CA, Al-Jader LN, May A, Hayes SL, Jackson HA \& Worwood M (2002) Hereditary haemochromatosis: only $1 \%$ of adult HFE C282Y homozygotes in South Wales have a clinical diagnosis of iron overload. Hum Genet 111, 538-543.

62. Hulthen L, Lindstedt G, Lundberg P-A \& Hallberg L (1998) Effect of mild infection on serum ferritin concentration clinical and epidemiological implications. Eur J Clin Nutr 52, 376-379.

63. Borel MJ, Smith SM, Derr J \& Beard JL (1991) Day-to-day variation in iron-status indices in healthy men and women. Am J Clin Nutr 54, 729-735.

64. Cooper MJ \& Zlotkin SH (1996) Day-to-day variation of transferrin receptor and ferritin in healthy men and women. Am J Clin Nutr 64, 738-742.

65. Cook JD, Skikne BS, Lynch SR \& Reusser ME (1986) Estimates of iron sufficiency in the US population. Blood 68, 726-731.

66. Murakami K, Sasaki S, Takahashi Y et al. (2008) Misreporting of dietary energy, protein, potassium and sodium in relation to body mass index in young Japanese women. Eur J Clin Nutr 62, 111-118. 